\title{
DRUG UTILIZATION STUDY OF PSYCHOTROPIC DRUGS PRESCRIBED IN PSYCHIATRY OPD OF L. N. MEDICAL COLLEGE ASSOCIATED J. K. HOSPITAL, BHOPAL DISTRICT, MADHYA PRADESH
}

\author{
Richa Chaturvedi ${ }^{1}$, Parag Sharma²
}

${ }^{1}$ Resident, Department of Pharmacology, L. N. Medical College Associated J. K. Hospital, Bhopal.

2Professor \& HOD, Department of Pharmacology, L. N. Medical College Associated J. K. Hospital, Bhopal.

ABSTRACT

\section{BACKGROUND}

Utilization pattern of drugs varies from place to place and is influenced by differing patient characteristics, type of disea se prevalent, cultural and environmental influences, socioeconomic states, availability of newer drugs and prescribing habit of physicians. Psychiatric disorders are one of the major causes of morbidity. Development of newer drugs like SSRIs and atypical antipsychotics has altered the treatment paradigms. Various factors like cost of drugs, local paradigms, etc. play a role in the selection of drug therapy and hence affect the outcome. Keeping this in mind, we conducted a study to delineate the various drug s used in psychiatric disorders. Psychotropic drugs have had a remarkable impact in psychiatric practice. However, their utilization in actual clinical practice, effectiveness and safety in real life situation needs continuous studies. So our aim to study the prevalence of psychiatric morbidity and analyse drug prescribing pattern in various psychiatric illnesses.

\section{METHODOLOGY}

A prospective cross sectional study was carried out for 6 months (Dec. 2014 - May. 2015) in psychiatry OPD of L. N. Medical College, Bhopal. Patients of all ages and both sexes were included in the study and 600 prescriptions were randomly selected.

\section{RESULT}

Antipsychotic drugs (75.33\%) were most frequently prescribed psychotropic drugs in various psychiatric disorders followed by Anti-Depressants (48.33\%) and Anxiolytics (26\%).

\section{CONCLUSION}

This study shows that antipsychotics are the most common antipsychotic drugs prescribed in patients with psychotic illness. Depression is the most common disease. Prescription rate was higher in men between 21-40 yrs. age.

\section{KEYWORDS}

Psychotropic Drugs, Effectiveness, Safety and Study.

HOW TO CITE THIS ARTICLE: Chaturvedi R, Sharma P. Drug utilization study of psychotropic drugs prescribed in psychiatry OPD of L. N. medical college associated J. K. hospital, Bhopal district, Madhya Pradesh. J. Evolution Med. Dent. Sci. 2016;5(51):32423244, DOI: $10.14260 /$ jemds/2016/752

\section{INTRODUCTION}

As per the World Health Organization (WHO), Drug utilisation study is defined as a study of marketing, distribution, prescription and uses of drugs in a society highlighting on the resulting medical, social and economic consequences. Drug utilisation studies afford a baseline reference point about the effect of diverse interventions in prescribing the concerned drugs. ${ }^{[1]}$ The main idea behind this is to make medical care rational and more cost-effective. Studies are necessary as these studies monitor, evaluate and suggest modifications to improve the prescribing habits. ${ }^{[2]}$ Drug utilisation studies facilitate the appropriate use of drugs; thereby, it can reduce the potential hazards to the patients and unnecessary expenses. So the periodic review of pattern of drug utilization helps to ensure safe and effective treatment.[3]

Financial or Other, Competing Interest: None.

Submission 25-02-2016, Peer Review 30-03-2016,

Acceptance 05-04-2016, Published 24-06-2016.

Corresponding Author:

Dr. Parag Sharma,

Sr. MIG-61, Sahyadri Enclave

Opposite Wireless Office,

Bhadbhada Road,

Bhopal-462003, Madhya Pradesh.

E-mail: gautamanand1234@gmail.com

DOI: $10.14260 /$ jemds/2016/752
Psychotropic medication is used when symptoms of mental or emotional illness are severe and interferes with normal functioning. Sometimes, these drugs are used for medical and neurological disorders. All drugs also require careful monitoring and evaluation regarding cost.[4] The clinical indication and monitoring are needed to avoid the inappropriate use, potential serious side and life-threatening effect.[5]

\section{MATERIALS AND METHOD \\ Study Design}

It was a prospective, non-comparative, observational, followup study, was carried out in Outpatient Department of Psychiatry, J. K. Hospital, L. N. Medical College, Bhopal.

\section{Duration of Study}

18 months (December 2014 to May 2015).

\section{Site of Study}

Department of Pharmacology and Department of Psychiatry, Tertiary Care Hospital, Bhopal district, Madhya Pradesh.

\section{Sample Size}

600 patients of all ages and both sexes were included in the study. Approval from the Ethical Committee to be taken from IEC, L. N. Medical College, Bhopal.

\section{Methods of Collection of Data}

The participants' diagnostic and clinical data including age, sex, type of psychiatric disorder and type of drug was noted down after taking written consent. 


\section{RESULT}

A total of 600 patients with a diagnosis of psychiatric disorders and who were receiving at least one antipsychotic drugs were included in the study.

\begin{tabular}{|c|c|c|}
\hline Age (Years) & No. of Patients & Percentage \\
\hline 0 to 20 & 54 & 9 \\
\hline 21 to 40 & 256 & 42.66 \\
\hline 41 to 60 & 198 & 33 \\
\hline$>60$ & 92 & 15.34 \\
\hline \multicolumn{2}{|c|}{ Table 1: Age Wise Distribution } \\
\hline
\end{tabular}

In this study, patients between 21 to 40 years of life formed majority of the patients accounting to $42.66 \%$ of the total patients.



\begin{tabular}{|c|c|c|}
\hline Sex & No. of Patients & Percentage \\
\hline Male & 434 & 72.33 \\
\hline Female & 166 & 27.67 \\
\hline \multicolumn{3}{|c|}{ Table 2: Sex Wise Distribution } \\
\hline
\end{tabular}

This table shows the sex distribution. Majority of the patients in our study were male $72.33 \%$ as compared to female $27.67 \%$, which reflects the population at risk. This male preponderance is seen in all age groups.

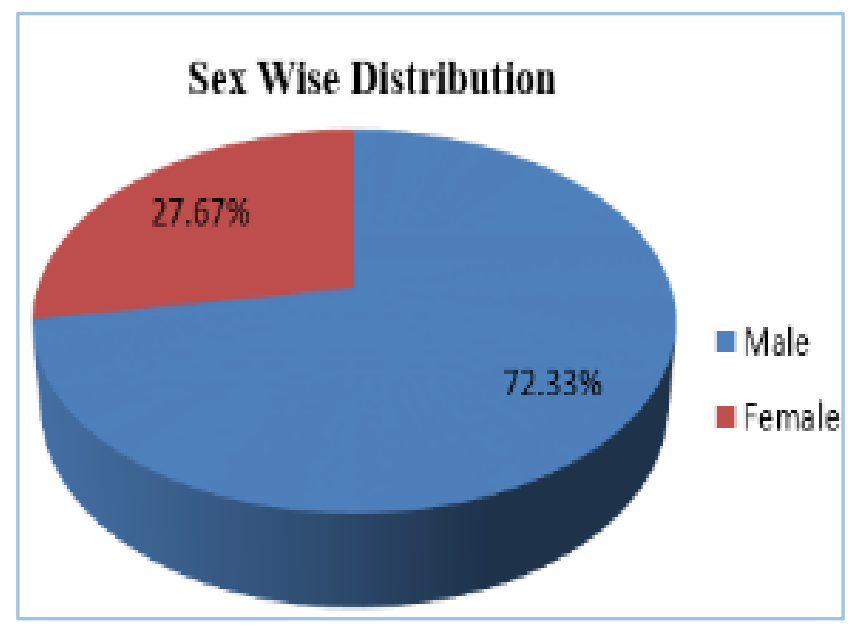

\begin{tabular}{|c|c|c|}
\hline $\begin{array}{c}\text { Psychiatric } \\
\text { Disorder }\end{array}$ & No. of Patients & Percentage \\
\hline Depression & 218 & 36.33 \\
\hline Anxiety & 165 & 27.5 \\
\hline Schizophrenia & 102 & 17 \\
\hline $\begin{array}{c}\text { Alcohol withdrawal } \\
\text { syndrome }\end{array}$ & 65 & 10.84 \\
\hline Insomnia & 32 & 5.33 \\
\hline Others & 18 & 3 \\
\hline Table 3: Prevalence of Psychiatric Disorder \\
\hline
\end{tabular}

This table shows the prevalence of psychiatric disorder. Most common disorders among the patients attending psychiatry OPD were Depression 36.33\%, Anxiety 27.5\%, Schizophrenia 17\%. The other common disorders were Alcohol withdrawal syndrome 10.84\%, Insomnia 5.33\% and others $3 \%$.

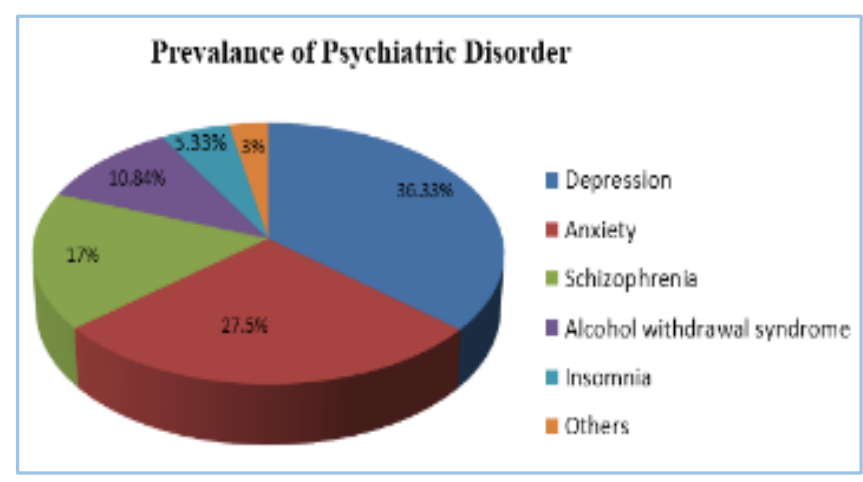

\begin{tabular}{|c|c|c|}
\hline $\begin{array}{c}\text { Category of } \\
\text { Drugs }\end{array}$ & $\begin{array}{c}\text { No. of } \\
\text { Patients }\end{array}$ & Percentage \\
\hline Anti-Depressants & 452 & 75.33 \\
\hline Anxiolytics & 290 & 48.33 \\
\hline Anti-Psychotics & 156 & 26 \\
\hline Anticholinergics & 103 & 17.16 \\
\hline Anti-manic/Mood Stabilizers & 73 & 12.16 \\
\hline \multicolumn{2}{|c|}{ Table 4: Category of Drugs Prescribed } \\
\hline
\end{tabular}

Most common drugs prescribed among the patients were Anti-Depressants 75.33\%, Anxiolytics 48.33\%, AntiPsychotics 26\%, Anticholinergics $17.16 \%$ and Antimanic/Mood Stabilizers $12.16 \%$.

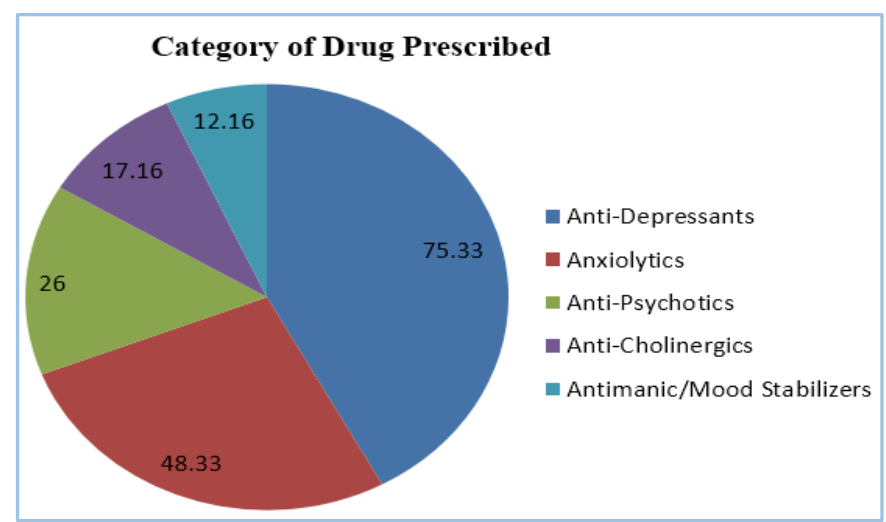




\begin{tabular}{|c|c|c|}
\hline Category & Drug & Percentage \\
\hline \multirow{7}{*}{ Antidepressants } & Fluoxetine & 42 \\
\hline & Imipramine & 22.2 \\
\hline & Sertraline & 11.4 \\
\hline & Amitriptyline & 10.2 \\
\hline & Mirtazapine & 9.2 \\
\hline & Paroxetine & 3.3 \\
\hline & Escitalopram & 1.7 \\
\hline \multirow{5}{*}{ Anxiolytics } & Lorazepam & 31 \\
\hline & Clonazepam & 27.9 \\
\hline & Chlordiazepoxide & 17.4 \\
\hline & Alprazolam & 17.1 \\
\hline & Clobazam & 6.6 \\
\hline \multirow[t]{9}{*}{ Antipsychotics } & Trifluoperazine & 42.5 \\
\hline & Chlorpromazine & 27.5 \\
\hline & Levosulpiride & 11.2 \\
\hline & Clozapine & 7.4 \\
\hline & Olanzapine & 5 \\
\hline & Risperidone & 2.2 \\
\hline & Aripiprazole & 1.9 \\
\hline & Fluphenazine & 1.4 \\
\hline & Haloperidol & 0.9 \\
\hline
\end{tabular}

Most common drugs prescribed among the patients were Anti-Depressants 75.33\% (Fluoxetine, Imipramine and Sertraline), Anxiolytics 48.33\% (Lorazepam, Clonazepam and Chlordiazepoxide), Anti-Psychotics 26\% (Trifluoperazine, Chlorpromazine and Levosulpiride), Anticholinergics $17.16 \%$ and Antimanic/Mood Stabilizers 12.16\%.

\section{DISCUSSION}

The burden of illness resulting from psychiatric and behavioural disorders is enormous, although it remains grossly underrepresented by conventional public health statistics. Some psychotropics are among the most commonly used ones, since polypharmacy leads to increased risk of drug interactions, increased hospital cost.[6] and errors of prescribing.[7]

In our study, depression is the most common psychotic illness. Same finding was observed in other studies. ${ }^{[8][9]}$

Men received more psychotropic prescriptions than women.[10][11] It is observed that female patients with psychotic disorder present with more severe mental deterioration in an advanced stage of the illness. This may be due to the lack of awareness by their family members and relatives or it may be due to higher depressive episodes in females due to increased hormonal influences.

Most commonly affected age group is between 21 to 40 years by any psychotic disorder. Increasing use of psychotropic drugs in this age group may be due to increased incidence of mental ill health, improved mental health literacy in general population, reduction in stigma associated with mental illness, increase in drug treatment option.[12]

The use of atypical antipsychotic drugs is favoured by most of the published guidelines.[13] In our study the majority of the patients $75.33 \%$ were receiving the antidepressant medications. This is due to the clinical efficacy and safety of new generation antidepressant medications.[14,15] Antidepressants and antipsychotic co-prescription may be prescribed to tackle the negative side effects of psychosis. The efficacy and safety of such co-prescription has been insufficiently investigated.

\section{CONCLUSION}

This study shows that antipsychotics are the most common antipsychotic drugs prescribed in patients with psychotic illness. Depression is the most common disease. Prescription rate was higher in men between 21-40 yrs. age.

To see the efficacy, adverse reactions, usage of various other psychotropic medications and their rational use, it is necessary to do more detailed study in large number of populations.

\section{REFERENCES}

1. Banerjee I, Roy B, Sathian B, et al. Socio demographic profile and utilization pattern of antipsychotic drugs among schizophrenic inpatients: a cross sectional study from western region of Nepal. BMC Psychiatry 2013;13:96.

2. Gupta N, Sharma D, Garg SK, et al. Auditing of prescriptions to study utilization of antimicrobials in a tertiary hospital. Indian J Pharmacol 1997;29(6):411-5.

3. WHO international working group for drug statistics methodology, WHO collaborating centre for drug statistics methodology, WHO collaborating centre for drug utilization research and clinical pharmacological services. Introduction to drug utilization research. Geneva: World Health Organization, 2003.

4. Miller AL, Craig CS. Combination antipsychotics: pros, cons and question. Schizopher Bull 2002;28(1):105-09.

5. Prueksaritanond S, Pumkompol T, Sukying C, et al. Psychotropic drug prescribing in the family medicine outpatient clinic, ramathibodi hospital. J Med Assoc Thai 2009;92(2):266-72.

6. Atanasova I, Terziivanov D. Investigation on antibiotics in a hospital for a one-year period. Int J Clin Pharmacol Ther 1995;33(1):32-3.

7. Pradhan SC, Shewade DG, Tekur U, et al. Changing pattern of antimicrobial utilization in an Indian teaching hospital. Int J Clin Pharmacol Ther Toxicol 1990;28(8):339-43.

8. Fourrier A, Gasquet I, Allicar M, et al. Pattern of neuroleptic drug prescription: a national cross sectional survey of a random sample of french psychiatrists. Br J Clin Pharmacol 2000;49(1):80-6.

9. Hugenholtz GWK, Stolker J, Heerdink E, et al. Short-acting parenteral antipsychotics drive choice for classical versus atypical agents. Eur J Clin Pharmacol 2003;58(11):75760.

10. Olfson M, Blanco C, Liu L, et al. National trends in the outpatient treatment of children and adolescents with antipsychotic drugs. Arch Gen Psychiatry 2006;63(6):679-85.

11. Tomasi R, De Girolamo G, Santone G, et al. The prescription of psychotropic drugs in psychiatric residential facilities: a national survey in Italy. Acta Psychatr Scand 2006;113(2):212-23.

12. Jorm A, Christensen $H$, Griffiths K. Changes in depression awareness and attitudes in Australia: the impact of beyondblue: the national depression initiative. Australian and New Zealand Journal of Psychiatry 2006;40(1):42-6.

13. Csernansky JG, Mahmoud R, Brenner R. A comparison of risperidone and haloperidol for the prevention of relapse in patients with schizophrenia. $\mathrm{N}$ Engl J Med 2002;346(1):16-22.

14. Serretti A, De Ronchi D, Lorenzi C, et al. New antipsychotics and schizophrenia: a review on efficacy and side effects. Curr Med Chem 2004;11(3):343-58.

15. Freedman R. Schizophrenia. N Engl J Med 2003;349:173849. 